\title{
Prevalence and Risk Factors of Urinary Tract Infection among Pregnant Women in Ismailia City, Egypt
}

\author{
Nora Refat Mohamed ${ }^{1}$, Hanan Hassan Hassan Omar ${ }^{2}$, \\ Inas Mohamed Abd-Allah ${ }^{3}$ \\ ${ }^{I}$ Maternity, Obstetric and Gynecological Nursing, Faculty of Nursing / Suez Canal University, Egypt \\ ${ }^{2}$ Lecturer, clinical pathology, Faculty of Medicine / Suez Canal University, Egypt \\ ${ }^{3}$ Asistant Professor,Maternity, Obstetric and Gynecological Nursing, Faculty of Nursing / Suez Canal \\ University, Egypt
}

\begin{abstract}
:
Background: urinary tract infection (UTI) is a commonly encountered disease during pregnancy in Egypt that can result in critical and costly complications for both mother and fetus which urge the need for timely detection and prevention. The study aimed to determine the prevalence and risk factors of urinary tract infection among pregnant women in Ismailia city. Design: descriptive cross-sectional design was utilized. Setting: urban and rural primary health care (PHC) centers and private centers in Ismailia city. Sample: purposive sampling was used to enroll 330 pregnant women.Tools: structured interviewing questionnaire and investigation record for urine analysis and culture. Results: $29 \%$ of the studied women had urinary tract infection. Factors associated with UTI during pregnancy were previous UTI history; maternal anemia; unhealthy urination habits; increase of sexual intercourse frequency; poor hygienic practices; child spacing less than two years; inadequate socioeconomic conditions; suboptimal nutritional habits; constipation; and family history. Frequency of urination followed by burning urination, then supra-pubic pain were the common complaints. Conclusion: UTI was prevalent among studied pregnant women. Presence of history of previous UTI, family history, short pregnancy spacing, poor general and dietary health behaviors and inadequate socioeconomic conditions were significant predisposing factors. Recommendations: Providing a health educational program about preventive measures of UTI for pregnant women. Periodical screening to assure timely detection and proper treatment of infected pregnant women.
\end{abstract}

Keywords: Pregnancy, Risk factors, Urinary tract infection (UTI)

\section{Introduction}

Urinary tract infection (UTI) describes microbial colonization or inflammation of the bladder (cystitis), urethra (urethritis), or renal pelvis and kidneys (pyelonephritis). UTIs are one of the most widely spread and costly medical complication of pregnancy, occurring in nearly $20 \%$ of all pregnancies. They are also accountable for $10 \%$ of all admissions to hospital during pregnancy ${ }^{[1,2,3,4]}$.

The anatomical and physiological changes that occur during pregnancy increase the liability to urinary tract infection. Relaxation of ureteric smooth muscle triggered by Progesterone may predispose to upper urinary tract dilation. bladder displacement superiorly and anteriorly by the growing uterus can also, lead to bladder emptying impairment, thereby stasis of urine as well as the increased condensation of glucose and amino acids found in urine during pregnancy increase possibility of UTI. These changes alongside with an already short urethra (3-4cm in females) increase the frequency of urinary tract infection during pregnancy ${ }^{[5,6,7]}$.

Urinary tract infections (UTIs) are the most prevalent bacterial infections encountered during pregnancy. It includes two groups: asymptomatic (ASB) and symptomatic bacteruria. Asymptomatic bacteruria is defined as the persistent presence of bacteruria within the urinary tract of women who have no symptoms. A specimen of clean voided urine containing more than 100.000 colonies per milliliter of a single organism is diagnostic. Symptomatic bacteruria combines lower UTI (cystitis) and upper UTI (pyelonephritis) ${ }^{[8,9]}$.

Cystitis is defined as infection limited to the bladder.In lower UTI, there are symptoms of local infection that include frequency, dysuria, urgency, suprapubic pain and hematuria. Besides, presences of 100.000 colonies in each milliliter of a one organism from a urine specimen obtained by either catheterization or by the clean-voided midstream method ${ }^{[8,10]}$.Pyelonephritis is defined as symptomatic urinary tract infection, especially parenchyma of the kidney. Pyelonephritis is considered the most dangerous form of urinary tract 
infections. In addition to positive urine culture, patients complain from systemic symptoms such as chills and fever. Also, there will be flank pain vomiting, malaise, and back pain markedly in the costovertebral angle ${ }^{[8,10]}$.

Urinary tract infections in pregnancy are among the most prevalent health problems worldwide, especially in developing countries. The prevalence of urinary tract infection during pregnancy in Egypt was $30.29 \%$ in Suez governorate and ranged between 22 to $35 \%$ in zagazig governorate. Asymptomatic bacteruria doubles Prevalence in pregnancy to $2 \%-15 \%$, and if left untreated, approximately $40 \%$ of those infected will develop an acute symptomatic UTI. Symptomatic lower UTI occurs in $1.3 \%$ to $3.4 \%$ of pregnant women. Pyelonephritis, kidney tissues and pelvis inflammation, occurs in $1 \%$ to $2 \%$ of pregnant women. ${ }^{[11,12,13}$, ${ }^{14}$ Prevalence of bacteruria during pregnancy rises with parity, lower socioeconomic status, sexual activity, diabetes mellitus, chronic urinary retention and sickle-cell trait and disease. Also pregnant women that were bacteruric as schoolgirls carry a remarkably greater risk of UTI during pregnancy. Other risk factors include, previous urinary tract infections history, young age, neuromuscular dysfunction bladder, structural disorders of urinary tract, renal stones, and catheterization ${ }^{[1,15,16]}$.

Consequences of UTI or neglected asymptomatic bacteriuria can be significant including elevated risk of pyelonephritis, premature labour, fetal death, and pregnancy induced hypertension. Studies reported characteristics of pyelonephritis in pregnancy in $20-40 \%$ of pregnant women with asymptomatic bacteriuria. The common maternal complications associated with pyelonephritis include septicemia, anemia, permanent renal impairment, and pulmonary insufficiency ${ }^{[4,5]}$.Urinary tract infection constitutes a serious maternal and fetal risk, thus their prevention or early treatment is essential. Antenatal nursing interventions include prenatal risk assessment which aims to detect women and fetuses at risk to foster risk optimal care that will improve the perinatal outcome. Therefore prevention of symptomatic UTIs is greatly assisted by nursing interventions. Other nursing roles include ensuring effectiveness of treatment and prevent involvement of upper urinary tract. The nurse will provide management of bothersome lower urinary tract infection (LUTS) and watch closely lab values, in addition to patient teaching that is indicated to reinforce self-advocacy so the client has prevention of recurrence $^{[4,8,17,18]}$.

\section{Significance ofthe Study}

Nurse's knowledge of prenatal risk assessment allows for proactiveplanning, individualizehealth education, and proper referral. Outcomes of risk assessment offer guidelines by which the efficiency of the care can be evaluated. Frequent and regular assessment of the prevalence, etiologic organism and predisposing factors of urinary tract infections in pregnancy in developing countries is recommended. In Egypt a national study of a wide scale that includes primary health care centers should be conducted to identify the group that is vulnerable for developing a UTI in the obstetric community ${ }^{[19,20,21]}$. So, this study was conducted to determine the potential prevalence and risk factors of urinary tract infection among pregnant women in Ismailia city.

\section{Aim of the study}

This study aimed to determine risk factors of urinary tract infection among pregnant women in Ismailia city, Egypt.

\section{Research questions}

1. What is the prevalence of urinary tract infection cases among pregnant women in Ismailia city?

2. What are the common organism(s) causing urinary tract infection in pregnancy?

3. What are the symptoms presentation of urinary tract infection related in pregnancy?

4. What are the potential risk factors of urinary tract infection among pregnant women in Ismailia city?

\section{Research design}

\section{Subjects and Methods} Settings

Descriptive cross sectional design was applied to achieve the stated aim.

The study was carried out at antenatal clinics of governmental primary health care centers and private antenatal clinics at Ismailia city that cover urban and rural districts. Health centers include Hay Elsalam, Elshik zaid, Elsabaa Banat and Elshohada health centers as urban districts. Elmanaif, Elmahsama, Abo khalifa and Abo Atwa health centers as rural districts. Private antenatal clinics include Dr. Hanan Hassan center and Dr.Ahmed Soliman center. The governmental and private health care centers are distributed all over Ismailia city that represents the high flow rate centers that accepted joining the study. 
Prevalence and Risk Factors of Urinary Tract Infection among Pregnant Women in Ismailia City,

\section{Sample size and technique}

Purposive sampling of 330 pregnant women was recruited for this study according to the inclusion and exclusion criteria. Inclusion criteria: All pregnant women irrespective of age, parity or gestational age were included. Exclusion criteria: Women have known underlying renal pathology, chronic renal disease, and renal transplant. Women have diabetes mellitus, Women under immunosuppressant therapy (as Azathioprine, used during pregnancy in the management of solid organ transplantation, inflammatory bowel disease (IBD), malignancy and rheumatic diseases) or antibiotics use of less than 7 days from the last antibiotic dose.

Sample size was calculated according to the following equation:

$\mathrm{n}=\left[\mathrm{z}_{-}(\propto \cdot \dot{2}) / \mathrm{E}\right] * \mathrm{P}(1-\mathrm{P})^{[22]}$

n: sample size.

$\mathrm{Z}_{\propto / 2}: 1.96$ (the critical value corresponding to $95 \%$ level of confidence).

E: degree of precision $=5 \%$.

$\mathrm{P}$ : prevalence of UTI among pregnant women $=30.29 \%{ }^{[12]}$.

According to previous equation, estimated sample size was 323 pregnant women. And after addition of $5 \%$ to compensate for dropout it was 340 pregnant women. Ten subjects were excluded because of contamination, and mixed infection giving sample size of 330 pregnant women.

\section{Tools of data collection:}

Two main tools were used to achieve the study aims.

I- Structured Interview questionnaire that developed by the researcher and consists of seven parts as the following:

Part 1: included socio- demographic data as (patient's age, education level, residence, occupation, and economic status, water supply, etc.).

Part 2: included obstetrical and gynecologic risk factors as parity, gravidity, abortion, gestational age, living children number, child spacing, and previous family planning methods.

Part 3: included questions about nutritional risk factors as nutritional habits (amount of water / day, regular eating of yogurt; and fruits, etc.).

Part 4: included questions about risk factors related to sexual activity and hygiene (frequency of intercourse, voiding before and after coitus, etc.)

Part 5: included questions about general hygienic behavior risk factors as type of under- garment, hand washing before and after toileting, perineal wiping practice after toileting, etc.

Part 6: included questions about previous history of urinary tract infection and its recurrence.

Part 7: included data about symptoms of urinary tract infection presented by pregnant women as (presence of burning sensation or pain during urination, presence of blood in the urine,frequency, urgency, incomplete voiding, and presence of suprapubic pain ...etc.).

\section{II-Physiologic measures record:}

It was used to record the results of physiologic measures as urine analysis and culture, and hemoglobin level.

\section{Content validity}

Data collection tools were reviewed by a panel of 5 experts in the maternity, obstetric, gynecologic nursing, and urology to ensure applicability, comprehensiveness, understanding, and ease of implementation of the tools.

\section{Pilot study}

A pilot study was carried out on $10 \%$ (34) of sample. It was conducted to test the applicability of the tools and feasibility of the study. According to the results of the pilot study, items were corrected, modified, omitted or added. It also helped in determining the time needed for interviewing and evaluating the suitability of settings to perform the interview and lab investigations. Pregnant women recruited in the pilot study were not enrolled in the study.

\section{Field work}

A total of 340 pregnant women were recruited from the study settings. From each health care center or clinic the same number of subjects was drawn (34). Data were collected using the pre constructed tools through face to face interview from December 2014 to May 2015. 
In the selected study settings the researcher introduced herself to pregnant women, and based on prementioned inclusion and exclusion criteria suitable subjects were excused to participate in the study. Written consent was taken from each woman after explaining the purpose and procedures of the study. Data were collected from the selected governmental centers on Saturdays, Sundays, Mondays, and Wednesdays, which were days allocated for pregnant women in these centers. Data from private antenatal clinics were collected along the week. As days with a high flow rate were similar, destination to centers was chosen randomly till reaching the planned number of subjects. The approximate time spent with each woman during the interview was 20-30 minutes. Number of women interviewed ranged between 2-8 pregnant women per day.

\section{Urine Sample collection}

Clean catch mid-stream urine specimen were collected by the women after explaining the technique of urine sample collection, which was through the following process:

1-thoroughWash hands with soap and water then dry.

2- Labial separation with one hand.

3- Clean with water Area around the urinary opening in back ward direction then dry thoroughly.

4- With separating the labia void the first 20 to $30 \mathrm{ml}$ in the toilet and then collect a sample of the remaining urine into a sterile universal utensil.

5- Close the cap of urine bottle immediately considering not to touch either the edge of the bottle or inner side of the bottle cap ${ }^{[23]}$.

\section{Specimen Transportation}

Urine specimens were put in ice box immediately after pregnant women handled them and were labeled with client's name, number and date. Urine examinations were performed at laboratories that follow the universal procedures for urine analysis and culture (Suez Canal university hospital laboratory and Al-Ismailia laboratory).Urine specimens were cultured within 4 hours of collection.

\section{Urine Specimens' Analysis and Culture}

Urine specimens were cultured by specialized chemist or lab technician when they were first opened then the specimens were sent for microscopic and dip stick urine analysis. Biochemical reagent strip (dipstick)were used to screen for presence of nitrite and leukocyte esterase (LE), microscopic examination for pus cell (pyuria) and red blood cells (RBCs) in urine. The urine specimens were inoculated on blood agar, MacConkey agar. The plates were put in incubator at $37^{\circ} \mathrm{C}$ for 24 hours under completely aerobic conditions. After 24 hours of incubation, the culture plates were examined macroscopically to evaluate the color, appearance, morphology, and size of the colonies. The bacterial isolates were diagnosed using standard bacteriological measures, including microscopic examination, Gram stain and biochemical tests. Antimicrobial susceptibility of isolates was tested to help ensure that appropriate and adequate antibiotic provided ${ }^{[24]}$.

\section{Ethical Consideration}

The research was approved by Committee of Research Ethics. .Written consents were obtained from the women after a concise explanation of the study with her right to withdraw at any time. Confidentiality of the women's data was maintained. Women under study were not exposed to any increased risk as a result of the study. The result from the study helped the patient in receiving appropriate treatment, hence beneficial.

\section{Statistical Analysis:}

Statistical Package for Social Science (SPSS), version 20.0 (statistical packages for social science) was used for the statistical analysis of the data that coded and entered into computer. Inferential statistics were used Chi-square to compare between two or more qualitative variables as well as we used T-test to compare between two quantitative variables. Statistical significance was considered at $\mathrm{p}$-value $<0.05$.

\section{Results}

Figure (1) illustrates that, more than two thirds of examined pregnant women didn't have urinary tract infection compared to more than one fourth were infected.

Figure (2) shows that, less than two thirds of infected pregnant women with urinary tract infection were symptomatic while more than one third of them had no symptoms of urinary tract infection.

Figure (3) shows symptoms among symptomatic infected pregnant women. The most frequent symptoms were frequency of urination followed by, burning urination, then supra-pubic pain, nocturia, and low back pain. 
Table (1) reveals that, the most frequent organism in positive infected cases was E. coli (47.4\%) followed by staphylococcus aureus $(22.1 \%)$, then klebsiella (9.5\%).

Table (2) shows that, the differences in these obstetric parameters among infected and non-infected women were statistically insignificant. Less than two thirds of pregnant women in the two groups were multiparas, the majority of them had no abortion, and less than half of them were in the 2nd trimester.

As shown in table (3), Logistic regression analysis was performed to find out the best predictor of UTI among pregnant women. When all variables were included in the logistic regression analysis model, this table shows that the highly significant factors predisposing for the development of urinary tract infection during pregnancy were increased frequency of sexual intercourse and decreased frequency of urination per day, followed by no post coital urination, forward direction of wiping the perineum, increased duration of voluntary delay of voiding and use of synthetic undergarment. The highest odd ratio was shown with the use of synthetic undergarment, those who used synthetic undergarment had 2.7 increased risk of UTI compared to those who used cotton undergarment.Another logistic regression model was performed to find out the best predictor of UTI among different covariates.

Table (4) shows that, presence of previous history of UTI, hemoglobin level $<11 \mathrm{mg} / \mathrm{dl}$, husband that didn't wash genitals before coitus, child spacing less than 2 years, inadequate type of water supply, pregnant women that didn't wash hands before urination, and no urination before sleeping were significant predictors of UTI when all variables were included in the model. The highest odd ratio was previous history of UTI where, those who have previous history of UTI have 3.2 increased risk of UTI compared to those who don't have previous history of UTI.

\section{Discussion}

Infection of the urinary tract (UTI) represents the most common medical complication of pregnancy and ranges from asymptomatic bacteruria to pyelonephritis. Pregnant women are at greater risk of UTIs, particularly because of the physiologic and anatomic changes that occur in normal pregnancy. Physiological changes of pregnancy increase vulnerability to the development of asymptomatic bacteruria to pyelonephritis with the resulting maternal morbidity and poor fetal outcomes ${ }^{[25,26,27]}$. The present study was conducted to determine the risk factors of urinary tract infection among pregnant women in Ismailia city. A descriptive crosssectional study was carried out on 330 pregnant women attending the antenatal care clinics at selected primary health care centers and private clinics in Ismailia city. Data were collected using the pre constructed tools through face to face interview. All subjects diagnosed by the urine culture the golden standard for UTI diagnostic criteria from December 2014 to May 2015.

Findings from the present study revealed that, more than one fourth of the pregnant women who attending the selected antenatal clinics at primary health care centers in Ismailia city had UTI. It occurs more frequently in pregnant women because of the anatomical and physiologic changes that occur in the renal system in pregnancy ${ }^{[28]}$. This result agrees with studies in Egypt at Zagazig University Hospital by Dimetry et al. (2007) $)^{[11]}$ and at El Sadat Family Health Unit in Suez Governorate by Mohammad (2013) ${ }^{[\mathbf{1 2}]}$ who reported prevalence of UTI was less than one third of the studied pregnant women. Also, Tamalli et al. (2013) ${ }^{\text {[29] }}$ reported UTI prevalence rate of less than one third among the pregnant women In Libya. On the other hand the prevalence was higher inAbakaliki Metropolis, Nigeria where nearly half of the pregnant women had UTI [30] .While UTI prevalence during pregnancy was less than one fifth of studied samples in Khartoum ${ }^{\text {[31] }}$, in Nairobi, Kenya $^{[32]}$ and in Abha, Saudi Arabia ${ }^{[33]}$.

From the researcher's point of view, this may be due to different geographical location and different population. Also the difference in UTI prevalence during pregnancy could be due to variations in UTI perception, screening method, and confounding factors such as parity, age, and pregnancy ${ }^{[34]}$.The findings of the present study revealed that, the most frequent organism in positive cases was E. coli followed by Staphylococcus aureus. These findings agree with previous studies in Pakistan and Nigeria. They found that staph aureus was the second most frequent organism following E.coli ${ }^{[35,36]}$. Jalali et al. (2013) ${ }^{[37]}$ also, observed an increasing trend in the prevalence of Staphylococcus aureus infection among asymptomatic pregnant women in Iran.

E.coli has been well recognized as the commonest classical causative agent of UTI. Staphylococci was usually considered as a rare etiologic agent of UTI except in Sudan, Uganda, and Saudi Arabia which need more 
focus on the similarities among these countries ${ }^{[33]}$.In Egypt previous studies found different results: Mohammad (2013) ${ }^{\left[{ }^{[12}\right]}$ found that E. coli was the only causative organism while, Dimetry et al., (2007) $)^{[11]}$ found that the commonest organisms were klebsiella followed by E.coli. From the researcher's point of view, this might be due to difference in the studied subjects that combined increased participants from rural areas with high levels of poor housing conditions and hygienic practices. Nworie et al. (2013) ${ }^{[30]}$ also, attributed this result to the level of staphylococcal infection in this study area and poor personal hygiene amongst others. Thedomination of Gram-negative UTI bacteria could be attributed to an increase in levels of amino acids and lactose during pregnancy that particularly encourages E. coli growth. It could also be due to infection by faecal contamination due to poor hygiene ${ }^{[38]}$.

The present study results showed that, more than one third of infected pregnant women had no symptoms of urinary tract infection. In the line with these results a study in Egypt by Mohammad (2013) ${ }^{[12]}$ reported that two fifth of pregnant women with urinary tract infection had no symptoms of urinary tract infection. This high percentage can lead to delay in diagnosis and treatment, and developing of complication ${ }^{\left[{ }^{[2]}\right.}$. On the other hand higher rates of asymptomatic bacteruria were reported by Boye et al., (2012) ${ }^{[39]}$ who revealed that more than half of the studied pregnant women had asymptomatic bacteruria in Ghana. Also,Okonko et al., (2009) ${ }^{[40]}$ study in Nigeria, found that $60 \%$ of infected women have no symptoms of UTI. While other studies reported lower rates of asymptomatic bacteruria during pregnancy as in Emirates, India, and Nigeria $\left(4.8 \%, 8.8 \%\right.$, and $14.6 \%$ respectively) ${ }^{[41,42,43]}$. From the researcher's point of view, this variation can be attributed to many factors such as geographical differences, ethnicity and setting of study (primary care, community based or hospital) and the differences in screening test (urine dipstick, microscopy, culture) ${ }^{[42]}$.

Regarding symptoms of UTI, this study revealed that the most frequent symptoms were frequency of urination followed by, burning urination, then supra-pubic pain, nocturia, and low back pain. Similar results were reported by Masinde et al. (2009) ${ }^{[44]}$ who found that frequency of urination followed by, burning urination, then supra-pubic pain were the most common symptoms of urinary tract infection among infected women in Tanzania. Amiri et al. (2009) ${ }^{[45]}$ also reported that frequency of urination was the most reported symptom but followed by lower abdominal pain, dysuria, and change in odor of urine. While in contrast, Mohammad (2013) ${ }^{[12]}$ reported that the most common symptoms of urinary tract infection among infected women were dysuria and increased frequency of micturition followed by suprapubic pain. From the researcher's point of view, this could be explained as frequency of urination is a common urinary symptom reported during normal pregnancy due to pregnancy changes in addition to the pathology of UTI, resulted in increased numbers of complaints about it.

Regarding water supply, this study findings show that inadequate water supply was associated with presence of UTI in pregnancy. Hooton \& Samadpour, (2005) ${ }^{[47]}$ reported that the main source for colonization and other pathogens is contaminated water and food. Uropathogenic E. coli might contaminate water or food via many paths, including sewage, domestic or wild animals, or food dealers ${ }^{[47]}$.

Considering obstetric risk factors as, gravidity; parity; previous abortions number of living children; and gestational age were not associated with UTI in this study. In the line with these findings, Masinde et al. (2009) $)^{[44]}$ as well as Hamadan et al. (2011) ${ }^{[31]}$ also reported that Parity and gestational age were not associated with UTI in Tanzania and Sudan. In Egypt, Mohammad, (2013) ${ }^{[\mathbf{1 2}]}$ showed that the majority of pregnant women with UTI were primigravidas with non-significant difference between infected and non-infected women. In Saudi Arabia, also the prevalence of UTI as to previous history of abortion and mean number of children were not found statistically significant ${ }^{[33]}$ On the other hand, Sharma et al. (2009) ${ }^{[47]}$ in the observation regarding the risk of urinary incontinence and other urinary problem which according to them increases with parity of $>3$ as compared to null parity. Similarly Onuoha and Fatokun (2014) ${ }^{[21]}$ reported that multiparity has an increased risk factor of developing bacteruria among pregnant women. While Emiru et al. $(\mathbf{2 0 1 3})^{[\mathbf{4 8}]}$ found that UTI is more common in primigravida. Dimetry et al. (2007) ${ }^{[11]}$ also, reported discordant findings regarding association of increased UTI with multigravidas, gestational age, and those who have more than one child relating the results to the age, recurrent exposure to stasis of urine, or former infections history.

The current study revealed that, there was significant association between Child spacing duration and UTI during pregnancy. Less than half of infected women had child spacing duration of $<2$ years. From the researcher's point of view, this may be due to Profound physiologic changes in urinary tract during pregnancy are more likely to occur in women who have pregnancies in rapid succession ${ }^{[45]}$. Also, these results may be attributed to improper use of contraceptive methods especially breast feeding, that was used by one fifth of the UTI positive cases in the present study, due to educational level and large sample from rural areas. This might 
be another perspective of the relation between contraceptive methods and UTI especially in pregnancy. AlJawadi (2012) ${ }^{[50]}$ also reported short child spacing ( $<2$ years) was seen among less than half of the pregnant women with UTI.Regarding maternal anemia, this study results revealed that Hemoglobin level $<11 \mathrm{mg} / \mathrm{dl}$ was significantly associated with UTI during pregnancy. Similar results were reported by Haider et al., 2010 ${ }^{[46]}$ in Pakistan and Emiru et al., $\mathbf{2 0 1 3}^{[48]}$ in Ethiopia who studied UTI among pregnant women. Also this study results agrees with studies of asymptomatic bacteruria among pregnant women by Sescon et al (2003) $\left.{ }^{[51}\right]_{\text {in }}$ Philippines, Enayat et al. (2007) ${ }^{[52]}$ in Iran and Taher et al., (2009) ${ }^{[53]}$ in Qatar. From the researcher's point of view, these results may be attributed to anemic women are immunosuppressed they are vulnerable to infections such as UTI ${ }^{[54]}$. On the other hand, a study by Kovavisarach et al., (2009) ${ }^{[55]}$ in Thailand reported the absence of association between anemia and UTI in pregnant women.

The current study revealed that, significant association was found between synthetic undergarment $(\mathrm{OR}=2.7)$ and UTI occurrence. From the researcher's point of view, this could be attributed to the fact that most mothers utilized undergarments made of non-cotton materials which are non-absorbent hence more vulnerable (Wamalwa et al., 2013) ${ }^{[32]}$. Studies by Dimetry et al. (2007) ${ }^{[11}$ in Egypt and by Wamalwa et al., (2013) ${ }^{[32]}$ in Kenya also reported that unsatisfactory personal hygiene and those mothers who usually use underwear clothes other than cotton were significantly associated with UTI occurrence. Forward direction of wiping the perineum area was significantly associated with UTI in the current study. These results were supported by Amiri et al. $(\mathbf{2 0 0 9})^{[45]}$, Moustafa \& Makhlouf (2012) ${ }^{[56]}$, and Almushait et al. (2013) ${ }^{[33]}$. From the researcher's point of view, these results explain the dominance of E.coli in this study as E.coli is a normal intestinal flora that might be forced to urethra via forward washing or drying perineal area ${ }^{[33]}$.

Voluntary urination delay and decreased frequency of urination were associated with UTI in women in the present study $(\mathrm{OR}=1.01)$. These finding agrees with other studies by Scholes et al. (2005) ${ }^{[57]}$ and Amiri et al. (2009) ${ }^{[45]}$ who reported that voluntary delay of evacuating the bladder increased the likelihood of UTI in pregnant women. From the researcher's point of view, this may be attributed to the fact that increased urination frequency washes the urinary tract and voluntary delay of urination, especially pregnant women nourishing rich urine, gives greater opportunity for microorganism's multiplication ${ }^{[58]}$. Increased frequency of sexual intercourse was significantly associated with UTI during pregnancy in the current study findings $(\mathrm{OR}=1.6)$. Similar results were reported byDimetry et al. (2007) ${ }^{[11]}$, Amiri et al. (2009) ${ }^{[45]}$ and Mohammad (2013) ${ }^{[12]}$ who found that frequency of sexual intercourse was associated with UTI. From the researcher's point of view, this could be due to the mechanical sexual manner which enhances entry of E. coli one of the uropathogenic bacteria (Amiri et al., 2009) ${ }^{[45]}$.

The current study findings showed that UTI was significantly associated with pregnant women who didn't void urine post coitus. UTI was also significantly associated with pregnant women whose husbands didn't wash genitals pre coitus. These findings were similar to studies by Dimetry et al. (2007) ${ }^{[11]}$, Amiri et al. $(\mathbf{2 0 0 9})^{[45]}$, Moustafa \& Makhlouf (2012) ${ }^{[56]}$ and Mohammad (2013) ${ }^{[12]}$. From the researcher's point of view, these findings support the association between hygiene practices, especially genital hygiene and UTI. Post coital urination was associated with UTI as reported by many studies in Egypt this may be attributed to wrong cultural beliefs that discourage post coital urination as stated by some women in this study.In this study, there was significant association between past history of UTI and UTI during pregnancy $(\mathrm{OR}=3.2)$. This result agrees with Haider et al. (2010) ${ }^{[35]}$ who reported that prevalence of bacteruria was among all women who had previous sprouts of UTI. Also, in study of Parveen et al. (2011) ${ }^{[59]}$ most of the studied women had past history of UTI. In addition, Masinde et al. (2009) ${ }^{[44}$ and Hamdan et al. (2011) ${ }^{[31]}$ mentioned that a history of previous UTI is an important risk factor for asymptomatic UTI.

\section{Conclusion \& recommendations}

Based on the findings the study concluded that, UTI remain a prevalent problem during pregnancy especially, in developing countries. Improper health behaviors and genital hygiene along with increased sexual activity, urination habits, socioeconomic level and dietary habits play significant role in the occurrence of UTI during pregnancy. These findings could be attributed to lack of knowledge about UTI risk factors and its prevention during pregnancy. Limitations of the study were unavailability of data about Body mass index (BMI) and blood group for all pregnant women thus these data was not covered in the presentstudy. In the light of the findings of the current study the researcher recommends: Providing a health educational program about preventive measures of UTI for pregnant women. Periodical screening of pregnant women for early detection and proper treatment. Further researches are recommended to:

- Periodic national studies of UTI in pregnancy to identify the prevalence and risky groups in Egypt. 
- Assess relation between Dietary factors and UTI during pregnancy in Egypt using standard measures for dietary intake.

- Assess relation between family and genetic factors, using blood group, and UTI during pregnancy especially with the high recurrence of UTI in Egypt emphasized by different studies.

- Assess factors leading to recurrence of UTI in obstetric population.

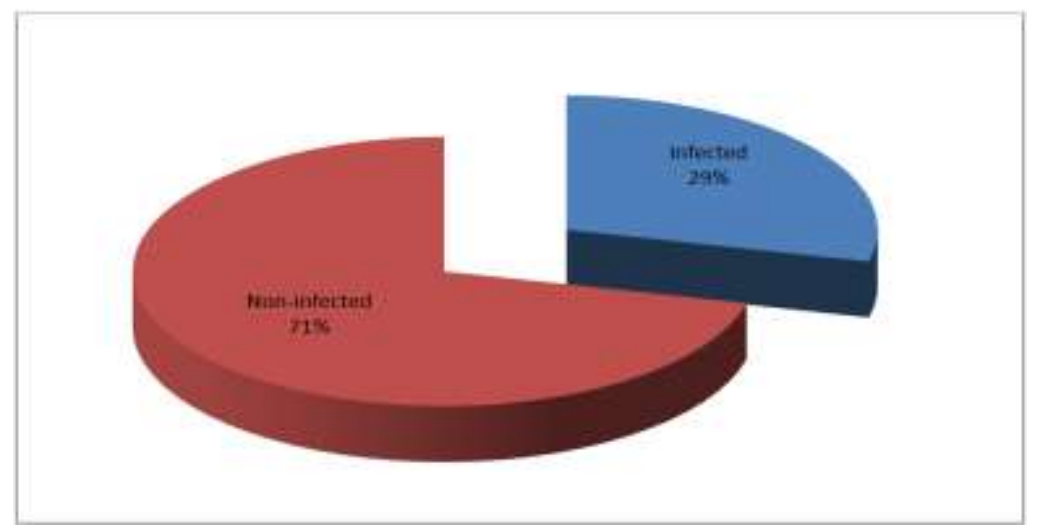

Figure (1): Distribution of pregnant women according to their urinary tract infection.

Table (1): Distribution of pregnant women with positive growth according to causative organism.

\begin{tabular}{|l|c|c|}
\hline \multirow{2}{*}{ Causative agent } & \multicolumn{2}{c|}{ Infected pregnant women(n = 95) } \\
\cline { 2 - 3 } & No. & \% \\
\hline E. coli & 45 & 47.4 \\
\hline Staph. Aureus & 21 & 22.1 \\
\hline Klebsiella & 9 & 9.5 \\
\hline Proteus & 6 & 6.3 \\
\hline Pseudomonas & 4 & 4.2 \\
\hline Serratia & 4 & 4.2 \\
\hline Citrobacter & 3 & 3.2 \\
\hline Acenitobacter & 2 & 2.1 \\
\hline Non-hemolytic streptococci & 1 & 1.1 \\
& & \\
\hline
\end{tabular}

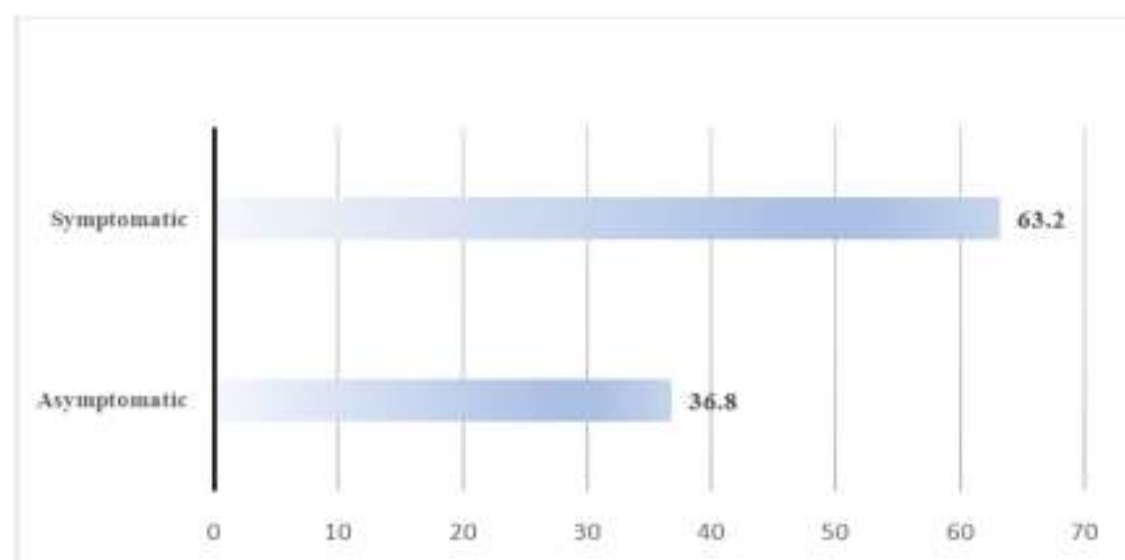

Figure (2): Distribution of infected women according to presence UTI symptoms. 


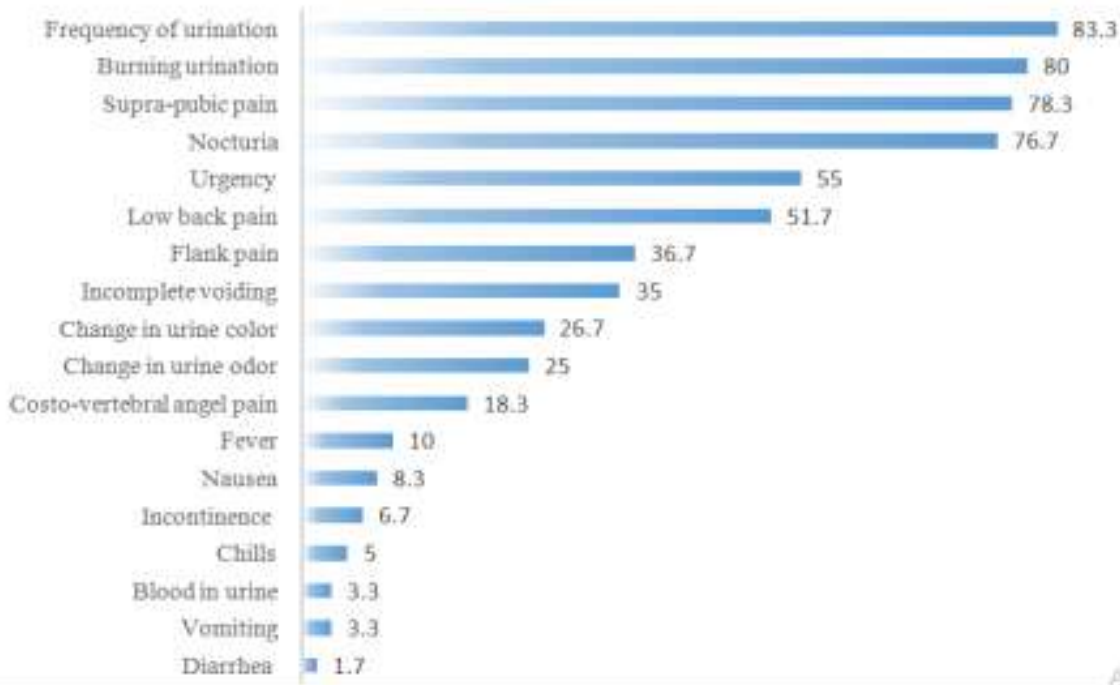

Figure (3): Distribution of symptomatic infected pregnant women according to symptoms of urinary tract infection $(n=60)$.

Table (2): Comparison between infected and non-infected pregnant women related to their obstetrical history.

\begin{tabular}{|c|c|c|c|c|c|c|c|}
\hline \multirow{2}{*}{\multicolumn{2}{|c|}{ Obstetric history }} & \multicolumn{2}{|c|}{$\begin{array}{c}\text { Infected } \\
(\mathbf{n}=95)\end{array}$} & \multicolumn{2}{|c|}{$\begin{array}{l}\text { Non- infected } \\
(\mathbf{n}=\mathbf{2 3 5})\end{array}$} & \multirow{2}{*}{$\begin{array}{c}\text { Statistical test } \\
\text { value }\end{array}$} & \multirow[t]{2}{*}{$p$-value } \\
\hline & & No. & $(\%)$ & No. & $(\%)$ & & \\
\hline \multirow{3}{*}{ Gravidity } & Primigravida & 38 & 40 & 90 & 38.3 & \multirow[b]{2}{*}{0.083} & $0.774^{1}$ \\
\hline & Multigravida & 57 & 60 & 145 & 61.7 & & \\
\hline & Mean \pm SD & \multicolumn{2}{|c|}{$2.07 \pm 1.1$} & \multicolumn{2}{|c|}{$2.25 \pm 1.31$} & 10562.500 & $0.424^{2}$ \\
\hline \multirow{3}{*}{ Parity } & Nullipara & 38 & 40 & 98 & 41.7 & \multirow[b]{2}{*}{0.529} & $0.861^{3}$ \\
\hline & Multipara & 57 & 60 & 137 & 58.3 & & \\
\hline & Mean \pm SD & \multicolumn{2}{|c|}{$0.95 \pm 0.96$} & \multicolumn{2}{|c|}{$1.04 \pm 1.08$} & 10793.500 & $0.620^{2}$ \\
\hline \multirow[t]{4}{*}{ Abortions } & No & 86 & 90.5 & 198 & 84.3 & \multirow{3}{*}{2.345} & \multirow[t]{3}{*}{$0.318^{3}$} \\
\hline & Once & 6 & 6.3 & 28 & 11.9 & & \\
\hline & $>1$ & 3 & 3.2 & 9 & 3.8 & & \\
\hline & Mean \pm SD & \multicolumn{2}{|c|}{$0.13 \pm 0.41$} & \multicolumn{2}{|c|}{$0.21 \pm 0.54$} & 10473.000 & $0.144^{2}$ \\
\hline \multirow{4}{*}{$\begin{array}{l}\text { Number of } \\
\text { living } \\
\text { children }\end{array}$} & No & 40 & 42.1 & 99 & $42.1 \%$ & \multirow{3}{*}{1.609} & \multirow[t]{3}{*}{$0.426^{3}$} \\
\hline & $1-3$ children & 55 & 57.9 & 131 & $55.7 \%$ & & \\
\hline & $>3$ children & 0 & 0 & 5 & $2.1 \%$ & & \\
\hline & Mean \pm SD & \multicolumn{2}{|c|}{$0.93 \pm 0.97$} & \multicolumn{2}{|c|}{$1.1 \pm 1.26$} & 10594.500 & $0.445^{2}$ \\
\hline \multirow{4}{*}{$\begin{array}{l}\text { Gestational } \\
\text { age in month }\end{array}$} & $1^{\text {st }}$ trimester & 24 & 25.2 & 62 & $26.4 \%$ & \multirow{3}{*}{0.192} & \multirow[t]{3}{*}{$0.909^{1}$} \\
\hline & $2^{\text {nd }}$ trimester & 41 & 43.2 & 107 & $45.5 \%$ & & \\
\hline & $3^{\text {rd }}$ trimester & 30 & 31.6 & 66 & $28.1 \%$ & & \\
\hline & Mean \pm SD & \multicolumn{2}{|c|}{$5 \pm 2.42$} & \multicolumn{2}{|c|}{$5.1 \pm 2.3$} & 11003.500 & $0.838^{2}$ \\
\hline
\end{tabular}

1. Chi square test;

3. Fisher's exact test;
2. Mann Whitney U test;

*statistically significant at $\mathrm{p}<0.05$.

Table (3): Logistic regression analysis for significant factors of urinary tract infection during pregnancy.

\begin{tabular}{|l|c|c|c|}
\hline \multicolumn{1}{|c|}{ Covariates } & $\mathbf{B}$ & $\boldsymbol{p}$-value & OR (95 \% CI) \\
\hline Decreased daily fluid intake & 0.236 & 0.342 & $1.266(0.778-2.058)$ \\
\hline Decreased drinking of fresh juices & 0.756 & 0.056 & $2.129(0.981-4.619)$ \\
\hline Drying perineum after urination & -0.220 & 0.177 & $0.803(0.584-1.104)$ \\
\hline Synthetic undergarment & 1.001 & $\mathbf{0 . 0 1 8}^{*}$ & $2.721(1.188-6.233)$ \\
\hline Forward direction of wiping perineum & -0.485 & $\mathbf{0 . 0 2 1}^{*}$ & $0.616(0.408-0.929)$ \\
\hline $\begin{array}{l}\text { Decreased frequency of urination per } \\
\text { day }\end{array}$ & -0.470 & $<\mathbf{0 . 0 0 1}{ }^{*}$ & $0.625(0.501-0.779)$ \\
\hline Voluntary delay of voiding & -0.156 & 0.472 & $0.855(0.559-1.310)$ \\
\hline Increased duration of voiding delay & 0.008 & $\mathbf{0 . 0 1 9}$ & $1.008(1.001-1.015)$ \\
\hline Increased sexual intercourse frequency & 0.457 & $<\mathbf{0 . 0 0 1}$ & $1.580(1.260-1.981)$ \\
\hline Presence of family history of UTI & 0.301 & 0.247 & $1.351(0.812-2.246)$ \\
\hline Constipation & 0.092 & 0.794 & $1.096(0.552-2.177)$ \\
\hline No urination after coitus & -0.289 & $\mathbf{0 . 0 0 8 *}$ & $0.749(0.606-0.926)$ \\
\hline $\begin{array}{l}\text { Increased frequency of previous attacks } \\
\text { of UTI }\end{array}$ & 0.308 & 0.301 & $1.360(0.759-2.436)$ \\
\hline
\end{tabular}


Prevalence and Risk Factors of Urinary Tract Infection among Pregnant Women in Ismailia City,

Table (4): Logistic regression analysis model (2) for significant factors of urinary tract infection during pregnancy.

\begin{tabular}{|c|c|c|c|}
\hline Covariates & B & $p$-value & OR $(95 \%$ CI $)$ \\
\hline secondary education level & 0.1 & 0.418 & $0.905(0.711-1.152)$ \\
\hline Inadequate type of water supply & 1.15 & $\mathbf{0 . 0 1 1}^{*}$ & $0.317(0.131-0.769)$ \\
\hline Inadequate type of sewage system & 0.207 & 0.442 & $0.813(0.479-1.378)$ \\
\hline Child spacing of less than 2 years & 0.223 & $0.006 *$ & $0.8(0.682-0.939)$ \\
\hline Hemoglobin level $<11$ mg/dl & 0.912 & $<0.001^{*}$ & $0.402(0.254-0.636)$ \\
\hline Decreased yoghurt intake & 0.033 & 0.587 & $0.968(0.859-1.09)$ \\
\hline No hand washing before urination & 0.823 & $0.017^{*}$ & $0.439(0.223-0.864)$ \\
\hline 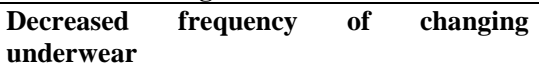 & 0.189 & 0.180 & $1.207(0.917-1.591)$ \\
\hline No urination before sleep & 0.479 & $0.036 *$ & $0.619(0.396-0.968)$ \\
\hline No urination before coitus & 0.134 & 0.251 & $0.875(0.696-1.099)$ \\
\hline Not washing genitals before coitus & 0.313 & 0.067 & $1.368(0.978-1.913)$ \\
\hline Husband not washing genitals before coitus & 0.459 & $\mathbf{0 . 0 0 1}^{*}$ & $0.632(0.478-0.835)$ \\
\hline Not washing genitals after coitus & 0.377 & 0.416 & $1.459(0.587-3.622)$ \\
\hline Husband not washing genitals after coitus & 0.433 & 0.342 & $0.649(0.266-1.584)$ \\
\hline Presence of previous history of UTI & 1.158 & $<0.001^{*}$ & $3.183(1.678-6.038)$ \\
\hline
\end{tabular}

\section{References}

[1] G. I. Benrubi,Hand book of obstetric and gynecologic emergencies (Philadelphia: Wolters Kluwer Lippincott Williams \& Wilkins, 2010) 120-133.

[2] T. Buttaro, J. Trybulski, P. Baily, \& J. Cook, Primary care: a collaborative practice. $4^{\text {th }}$ ed., (St. Lois: Elsevier Mosby, 2013) 59, 732:740.

[3] P. Duff, maternity and fetal infections. In R. K. Creasy, R. Resnik, J. D. Iams, C. J. Lockwood, T. R. Moore, \& M. F. Greene, Creasy \& Resnik's maternal-fetal medicine principles and practice. $7^{\text {th }}$ ed., (Philadelphia: Saunders, 2014).

[4] D. L. Lowdermilk, S. E. Perry, M. C. Cashion, \& K. R. Alden, Maternity and women's health care. $11^{\text {th }}$ ed., (St. Lois: Elsevier, 2014) 283:299, 317, 728:731.

[5] A. Rané, \& R. Dasgupta, urinary tract infection: clinical perspectives on urinary tract infection. (London: springer-verlag 2013) 1:5, $25: 31$.

[6] R. K. Creasy, R. Resnik, J. D. Iams, C. J. Lockwood, T. R. Moore, \& M. F. Greene, Creasy \& Resnik's Maternal- Fetal Medicine Principles and Practice. $7^{\text {th }}$ ed., (Philadelphia: Saunders, 2014) 816:820, 949: 951.

[7] E. K. Johnson, \& E. D. Kim, (2015):Urinary Tract Infections in Pregnancy. Available at http://emedicine.medscape.com. Accessed 30-6-2015 at $5.00 \mathrm{pm}$.

[8] S. E. Perry, M. J. Hockenberry, D. L. Lowdermilk, \& D. Wilson, Maternal child nursing care. Pregnancy. $5^{\text {th }}$ ed., (Philadelphia: Mosby Elsevier2014)200: 201, 332:340.

[9] N. Malhorta, R. Puri, \& J. Malhorta, Donald School manual of practical problems in obstetrics (New Delhi: Jaypee Brothers Publishers, 2012)137: 138.

[10] N. Gleicher, Principles of medical therapy in pregnancy (New York: Springer science \& Business Media 2012) 395, 629: 633, 793.

[11] S. R. Dimetry, H. M. El-Tokhy, N. M. Abdo, M. A. Ebrahim, \& M. Eissa, Urinary Tract Infection and Adverse Outcome of Pregnancy. J Egypt Public Health Assoc82 (3), 2007,203-218.

[12] N. A. Mohammad, A study of frequency and some risk Factors of Urinary Tract Infection among Pregnant Women Attending El Sadat Family Health Unit in Suez Governorate. Unpublished thesis, zagazig Un. Fac. Medicine, M.Sc., 2013.

[13] P. N. Baker, A. S. McEwan, S. Arulkumaran, T. A. Mahmood, F. Reid, M. I. Shafi, \& C. Aiken, Obstetrics Prepare for the MRCOG Key Articles from the Obstetrics (Philadelphia, Elsevier Health Sciences, 2015)123 125, 321- 324.

[14] S. L. Ward, S. M. Hisley, \& A. M. Kennedy, Maternal-child nursing care optimizing outcomes for mothers, children, \& families. $2^{\text {nd }}$ ed., (Philadelphia, F. A. Davis, 2015)365-366.

[15] A. R. Mundy, J. Fitzpatrick, D. E. Neal, \& N. J. R George, the scientific basis of urology. Urinary tract infection. ${ }^{\text {rd }}$ ed., (New York, CRC Press, 2010)131-161.

[16] N. J. Cibulka, \& M. L. Barron, Guidelines for nurse practitioners in ambulatory obstetric settings (New York, Springer Publishing Company, 2013)198-203.

[17] Nursing consult (2014) Renal Disease, Manual of High Risk Pregnancy and Delivery. Available at http//www.nursingconsult.Com/nursing/books. Accessed at 23/5/2014, $613 \mathrm{pm}$.

[18] S. L. Lewis, S. R. Dirksen, M. M. Heitkemper, \& L. Bucher Medical-surgical nursing assessment and management of clinical problems. $9^{\text {th }}$ ed., (St. Lois, Elsevier, 2014)1065-1073.

[19] M. El-Sokkary, Prevalence of Asymptomatic Bacteriuria in Antenatal Women with Preterm Labor at an Egyptian Tertiary Center. Journal of American Science7(4), 2011, 605-610.

[20] K. R. Simpson, \& P. A. Creehan, Perinatal Nursing. 4th ed., (Philadelphia, Wolters Kluwer health / Lippincott Williams \&Wilkin's, 2014) $77-79,89-120$.

[21] S. C. Onuoha, K. Fatokun, Prevalence and antimicrobial susceptibility pattern of Urinary Tract Infection (UTI) among pregnant women in Afikpo, Ebonyi State, Nigeria. American Journal of Life Sciences2(2), 2014, 6-52.

[22] Dawson, B. \& Trapp, R. G. Basic \& Clinical Biostatistics. $4^{\text {th }}$ ed., (USA, McGraw-Hill, 2004).

[23] C. Higgins, Urine microscopy, culture and sensitivity, understanding laboratory investigations a guide for nurses, midwives and healthcare professionals. $3^{\text {rd }}$ ed., (Oxford, john Wiley \& sons ltd, UK, 2013) 325-337.

[24] M. Cheesbrough, Microbiological tests. District Laboratory Practice in Tropical Countries, Part 2, $2^{\text {ed }}$ ed., (Cambridge, Cambridge University press, 2006) 105 114,157159,156, 178179, 187189, 194195.

[25] R. B. Taylor, A. K. Daid, S. A. Fields, D. M. Philips, \& J. E. Scherger, Family medicine principles and practice. $6^{\text {th }}$ ed., (New York, Springer Science \&Business Media, 2003) 93-94, $104-105$.

[26] H. Deshpande, Textbook of high risk pregnancy. (New Delhi, Jaypee Brothers Publishers, 2011)97-99.

DOI: 10.9790/1959-0603076272 $\quad$ www.iosrjournals.org $71 \mid$ Page


[27] J. M. Rowińska, J. Małyszko, \& M. Wieliczko, Urinary tract infections in pregnancy old and new unresolved diagnostic and therapeutic problems. Arch Med Sci. 11(1), 2015,67-77.

[28] J. Bothamley, \& M. Boyle, Medical conditions affecting pregnancy and childbirth. (Oxford, Radcliffe publishing, 2009)118-119.

[29] M. Tamalli, B. Sangar, \& M. A. Alghazal, Urinary tract infection during pregnancy at Al-khoms, Libya. International Journal of Medicine and Medical Sciences 3 (5), 2013, 455-459.

[30] A. Nworie, \& U. A. Eze, Prevalence and Aetiologic Agents of Urinary Tract Infection in Pregnancy in Abakaliki Metropolis. Continental J. Medical Research 4, 2010,18-23.

[31] Z. Hamdan, H. M. Abdel, K. A. Salah, \& A. Ishag, Epidemiology of UTIS and antibiotics sensitivity among pregnant women at Khartoum North hospital . Annals of Clinical Microbiology and Antimicrobials, 2011, 102.

[32] P. Wamalwa, J. Omolo, \& A. Makokha, Prevalence and risk factors for urinary tract infections among pregnant women. Prime Journal of Social Science (PJSS)2(12), 2013,524-531.

[33] M. A. Almushait, H. A. Mohammed, D. A. Al- Harthy, \& A. M. Abdullahd, Prevalence and Predisposing Factors of Urinary Tract Infections among Pregnant Women in Abha General Hospital. International Journal of Sciences Basic and Applied Research (IJSBAR)11(1), 2013,18-29.

[34] S. A. Al Sibiani, Asymptomatic bacteriuria in pregnant women in Jeddah, Western Region of Saudi Arabia Call for assessment. JKAU Med. Sci., 17(1), 2010, 29-42.

[35] G. Haider, N. Zehra, A. A. Munir, \& A. Haider, Risk factors of urinary tract infection in pregnancy. J Pak Med Assoc60 (3), 2010, 213-216.

[36] A. A.Turay, S. O. Eke, P. O. Oleghe, \& M. C. Ozekhome, The prevalence of urinary tract infections among pregnant women attending antenatal clinic at Ujoelen primary health care center, Ekpoma, Edo State, Nigeria. International Journal of Basic, Applied and Innovative Research; 3(1), 2014, 86 - 94.

[37] M. Jalali, M. Shamsi, N. Roozbehani, \& K. Kabir, Prevalence of Urinary Tract Infection and Some Factors Affected in Pregnant Women in Iran Karaj City 2013. Middle-East Journal of Scientific Research; 20 (7), 2013, 781-785.

[38] C. H. Obiogbolu, I.O. Okonko, C.O. Anyamere, A. O. Adedeji, A. A. Akanbi, J. E. Ogun, \& T. O. Faleye, Incidence of urinary tract infections (UTIs) among pregnant women in Akwametropolis, Southeastern Nigeria. Scientific Research and Essay, 4 (8), 2009, $820-824$.

[39] A. Boye, P. M. Siakwa, J. N. Boampong, G. A. Koffuor, Ephraim, R. K. D Amoateng, P. Obodai, \& G. Penu, Asymptomatic urinary tract infections in pregnant women attending antenatal clinic in Cape Coast, Ghana. Journal of Medical Researchl(6), 2012, 074-083.

[40] I. O. Okonko, L. Ijandipe, \& O. Ilusanya, Incidence of urinary tract infection (UTI) among pregnant women in Ibadan, SouthWestern Nigeria. Afr J Biotechnol 8, 2009, 6649-6657.

[41] S. Hazhir, Asymptomatic bacteriuria in pregnant women. Urol J. 4(1), 2007, 24-27.

[42] J.O. Odigie, \& K. C. Anugweje, Asymptomatic bacteriuria in pregnancy in Port Harcourt. Asia Pacific J Trop Med. 3(7), 2010, 580583.

[43] G. Ankur, S. Namita, G. Sapna, P. Anu, M. Neha, S. Daniya, A. Khushi, And S. Saroj, Prevalence of Asymptomatic Urinary Tract Infections in the Three Trimesters of Pregnancy. International J Current Microbiology Applied Sciences, 2015, 110-117.

[44] A. Masinde, B. Gumodoka, A. Kilonzo, \& S. E. Mshana, Prevalence of urinary tract infection among pregnant women at Bugando Medical Centre, Mwanza, Tanzania. Tanzan J Health Res, 11(3), 2009, 154-9.

[45] F. N. Amiri, M. H. Rooshan, M. H. Ahmady, \& M. J. Soliamani, Hygiene practices and sexual activity associated with urinary tract infection in pregnant women. Eastern Mediterranean Health Journal15(1), 2009, 104-110.

[46] T. M. Hooton, \& M. Samadpour, Is Acute Uncomplicated Urinary Tract Infection a Foodborne Illness, and Are Animals the Source. Clinical infectious diseases.40 (2), 2005, 134- 143.

[47] J. B. Sharma, S. Aggarwal, S. Singhal, S. Kumar, \& K. K. Roy, Prevalence of urinary incontinence and other urological problems during pregnancy a questionnaire based study.Arch Gynecol Obstet.279(6), 2009, 845-851.

[48] T. Emiru, G. Beyene, W. Tsegaye, \& S. Melaku, Associated Risk Factors Of Urinary Tract Infection Among Pregnant Women At FelegeHiwot Referral Hospital, Bahir Dar, North West Ethiopia. BMC Research Notes6, 2013,292.

[49] J. E. Bennett, R. Dolin, M. J. Blaser, Principles and practice of infectious diseases. 8th ed., (Philadelphia, Saunders, 2015) 905-906.

[50] D. A. Al-Jawadi, Urinary tract infections among pregnant women in Mosul city. Annals of the College of Medicine Mosul38(2), 2012, 35- 39 .

[51] N. I. Sescon, F. D. Garingalao-Molina, C. E. Ycasiano, M. C. Saniei, \& R. M. Manalastas, Prevalence of asymptomatic bacteriuria and associated risk factors in pregnant women. Philippine J Microbial infect Disease32(2), 2003,63-69.

[52] K. Enayat, F. Fariba, \& N. Bahram, Asymptomatic bacteruria among pregnant women attending antenatal clinic at Komfo Anokye teaching hospital, Kumasi, Ghana. Ghana Med J 4, 2007,126-29.

[53] M. A. Taher, F. M. Al-Meer, M. G. Al-Kuwari, \& M. F. Ismail, Prevalence and predictors of asymptomatic bacteruria among pregnant women attending primary health care in Qatar. Middle East J Fam Med7, 2009,10-13.

[54] S. Trivedi, \& M. Puri, Management of high risk pregnancy-a practical approach. (New Delhi, Jaypee Brothers Publishers, 2010)179, 278

[55] E. Kovavisarach, M. Vichairprunk, S. Kanjarahareutai, Risk factors related to asymptomatic bacteruria in pregnant women. $J$ Med Assoc Thai, 92, 2009, 606-610.

[56] M. F. Moustafa, \& E. M. Makhlouf, Association between the Hygiene Practices for Genital Organs and Sexual Activity on Urinary Tract infection in Pregnant Women at women's Health Center, at Assiut University Hospital. Journal of American Science8(9), 2012, $515-522$.

[57] D. Scholes, T. M. Hooton, P. L. Roberts, A. E. Stapleton, K. Gupta, \& W. E. Stamm, Risk factors associated with acute pyelonephritis in healthy women. Annals of internal medicine, 14, 2005, 220-7.

[58] G. Leifer, nursing care of women with complications during pregnancy. Introduction to maternity and pediatric nursing.. $7^{\text {th }}$ ed., (St. Louis, Elsevier Saunders, 2015)107.

[59] K. Parveen, A. Momen, A. A. Begum, \& M. Begum, Prevalence of Urinary Tract Infection during Pregnancy. J. Dhaka National Med. Coll. Hos.17 (02), 2011, 8-12. 